\title{
THE NUTRITION SOCIETY IN THE I9808: THE QUESTIONNAIRE ANALYSIS
}

\author{
By Margaret Ashwell and T. J. Cole, MRC Dunn Nutrition Unit, Milton \\ Road, Cambridge $\mathrm{CB}_{4}$ IXI
}

\section{Contents}

I. Background

2. Who are we?

3. What jobs do we do?

4. What qualifications do we have?

5. What are our interests in nutrition?

6. Do we want joint meetings with other societies?

7. What are our views on important issues in the 1980 s?

(i) Analysis procedure

(ii) Should the Nutrition Society provide some type of forum for the discussion of nutritional controversies?

(iii) Should the Nutrition Society do more for its overseas members?

(iv) Should the Nutrition Society do more to improve employment prospects for those trained in nutrition?

8. How reliable is questionnaire analysis?

9. Conclusions

Io. Acknowledgements

\section{Background}

In his Presidential Address at the AGM in May 1984 , Professor John Waterlow made us take a serious look at the Nutrition Society and how it functions. He stated his concern that the Society may not be meeting the needs and wishes of its members as fully as it might. First, he thought it seemed unrealistic to try to think about such matters without knowing more about the composition of the Society. Who are we? How far do we cover the wide spread of disciplines and activities with which nutrition is concerned? Once we know the answer to some of these questions he felt it would be appropriate to raise three questions:

(a) Should the Society be more involved in current controversies about nutrition policy?

(b) Are our international relations adequate, both with other industrial countries and with the Third World?

(c) Should the Society be concerned with the problem of careers in nutrition?

'Honorary Secretary of the Nutrition Society (1984- ), Room 194, Fifth Floor, Grosvenor Gardens House, 35-37 Grosvenor Gardens, London SW I W oBS. 
Professor Waterlow's address was followed by a lively discussion and, at the end of this, he encouraged us all to disperse to our various parts of the country, to stimulate further discussion amongst our colleagues on these particular topics and to report back any consensus of opinion (or otherwise) so that a specially arranged Council meeting in September 1984 could discuss the issues in greater detail. To a certain extent this happened and Council was able to consider reports of informal meetings which had been held during the summer at Bristol, Southampton and London. It was at this meeting too that I (M.A.) first proposed the idea that the Society could find out more about its members and what they thought, using the questionnaire method. I had prepared a rough draft of a list of questions that I thought should be included and I asked for Council's permission to work on this questionnaire, along with my colleague and co-author $\mathrm{Dr}$ Tim Cole, and to distribute it to all members of the Society. Permission was given and so, in the next few months, we compiled the questionnaire which is reproduced in Fig. I. During this time we not only called on fellow Nutrition Society officers for their criticisms of the questions we had asked, but we also persuaded friends at the Dunn Nutrition Unit to fill in 'dummy' questionnaires for us so that we could judge how sensible, or otherwise, were our questions. To all these long suffering people, we give sincere thanks.

In the second week of December 1984 we were in a position to distribute the questionnaires to all members of the Society. I remember a lot of discussion about the pros and cons of including a stamped addressed envelope to ensure a good response rate but in the end this idea was abandoned and we hoped that a nice encouraging letter from the President together with the offer of refunds of Nutrition Society Membership to five lucky respondents would act as a sufficient incentive for a good response. I can remember being somewhat worried at the time about sending the questionnaire out so close to Christmas but I realized that the chances of someone filling it in and getting it out of the way before the Christmas break were probably about equal to the chances of it being put on the pile 'to be looked at in the New Year!' Strangely enough, this is probably what did happen since a large number of questionnaires were returned to the Nutrition Society office by early January followed by a lull before another large batch was returned at the end of January. In fact by early February half had been returned; enough to feel that the whole exercise had been worthwhile and enough to feel that we could justify a follow-up letter to the non-responders urging them to fill in the second questionnaire which we were sending to them to replace the first which had obviously been mislaid. This certainly chivied up the response rate (and produced a few irate phone calls from people who were not pleased to get a second questionnaire when they insisted they had sent us the first!) and by the end of May 1985 we had received the grand total of 1257 questionnaires. Considering that our total membership for the year $1984-85$ was 1621 , this final response rate of $78 \%$ was, we felt, a truly magnificent response and one that justified a lot of time and effort on the analysis. 
SECTION ONE Plasen writs your reptios on the dotted lines or put letters in the baxes where appropriste

1. Surname

(Other names)

2. Address*

(Postcode, Zip code) (Country)

\section{Sex [M]ale [F]emale}

4. Age group:

$\begin{array}{ll}\text { Under } 25 & \text { (A) } \\ 25-44 & \text { (B) } \\ 45-64 & \text { (C) } \\ 65 \text { and over } & \text { (D) }\end{array}$

5. Nationality

6. In which year (roughly) did you first become a member of the Nutrition Society?

7. Could you please list your formal qualifications?

$$
\text { Qualification }
$$

Main subject

8. Are you:

a student member of the Society

a full member of the Society

a retired member of the Society

9. Are you. or have you ever been:

an officer of the Society

a member of the Society's Council

a member of the Editorial Boerd of the British Journal of Nutrition

an organiser of a symposium

a member of the Programmes Committee

none of these

10. If you are a full member, could you please give us some details about your present job?

(a) What does your job mainly involve? (just one answer, please)

Teaching

Clinical medicine

Research, clinical/human

Research, animal

Industry

Administration

Dietetics

Other (please write $H$ in the box and specify below)

(b) Is your present job permanent? [Y]es [N]o

11. Would you find it useful if the Nutrition Society produced an updated list of Members which included their flelds of interest [Y]es [N]o

12. Could you please define your fields of nutitional interest in one or more (up to five) key words or short phrases: 
13. Do you think that the Society should arrange more joint meetings with other Societies? [Y]es [N]o

14. If the Society decides to arrange more joint meetings with other British Societies, which of those that you belong to might be appropriate?

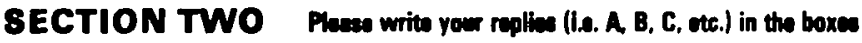

For all statements in this section, please record your agreement or disagreement in the following way:
Yes, I agree strongly
(A)
Yes, I agree
I have no definite opinion
No. I disagree
No, I disagree strongly

16. The Nutrition Society should provide some type of forum for the discussion of nutritional controversies? (e.g. the recommendations made on national food policies). If No to 0.15 skip to 0.19

16. Such a forum should take the form of a formal debate

17. Such a forum should take the form of an open discussion

18. Such a forum should aim, where possible, to produce a resolution or arrive at a policy decision if appropriate

19. The Society should sometimes set up working parties to discuss and report on certain areas of nutritional controversy

20. At present, the Society's regular symposia receive no media coverage; this policy should change

21. If the Society did organise some type of forum on nutritional controversies, media coverage should be considered

22. In view of the varying ways in which some words connected with Nutrition (e.g. those relating to recommended allowances) are used, the Nutrition Society should discuss and produce public definitions for such words

23. Our links with the Nutrition Societies of other countries are sufficient

24.f The Nutrition Society could do more for its overseas members

25. Money allowing, the Nutrition Society should invite more overseas speakers to its Symposia

26. The Nutrition Society should hold more of its Symposia on 'overseas' problems

27. The Nutrition Society should attempt to improve employment prospects for those trained in Nutrition

28. There is a need for a professional organisation, such as the Association of Chartered Accountants or the Institute of Electrical Engineers, to give status to those trained in nutritional science.

Fig. 1. The Nutrition Society questionnaire. 


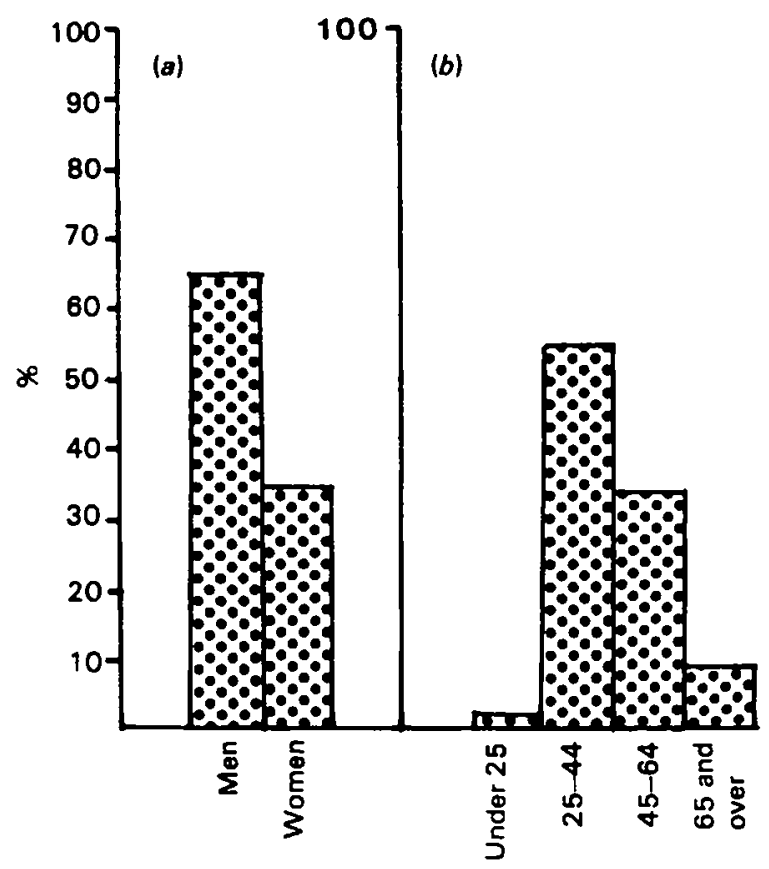

Fig. 2. Questionnaire respondents ( $n$ 1 257) by (a) sex and (b) age group.

\section{Who are we?}

Fig. 2 summarizes the information on sex and age of Nutrition Society members who filled in the questionnaire (referred to as members from now on for the sake of simplicity). It shows that, overall, men outnumber women by nearly two to one and that the majority of our members fall into the age range $25-64$. In the younger age group (i.e. under 45 ) there is greater equality in the numbers of men and women. In subsequent analysis, we talk about just two age groups: 'young' (under 45 ) and 'not so young' ( 45 or over). This subdivision not only simplifies the analysis but allows us (MA and TJC) to sneak into the 'young' group (justl) whilst, we hope, causing no offence to our elders!

Fig. 3 shows that in the very early days of the Nutrition Society (i.e. the 1940s) the ratio of men:women was only 1.5 ; this ratio in new members rose to 2.9 during the rg6os, but has decreased since then and is now only I. 3 . In fact if the ratio of men:women joining the Nutrition Society in the $1980 \mathrm{~s}$ is calculated for the under $45 \mathrm{~s}$, it comes right down to $I \cdot 1$ whereas for the over $45^{8}$ joining in the 1980 , the men outnumber the women by 4.8 to 1 .

Table I summarizes the information we received about where our members live. In all, a total of sixty-seven countries were mentioned. About three-quarters of our members live within the UK and about $6 \%$ of them live elsewhere in Europe. North America accounts for $8 \%$ and Australasia for $6 \%$. 


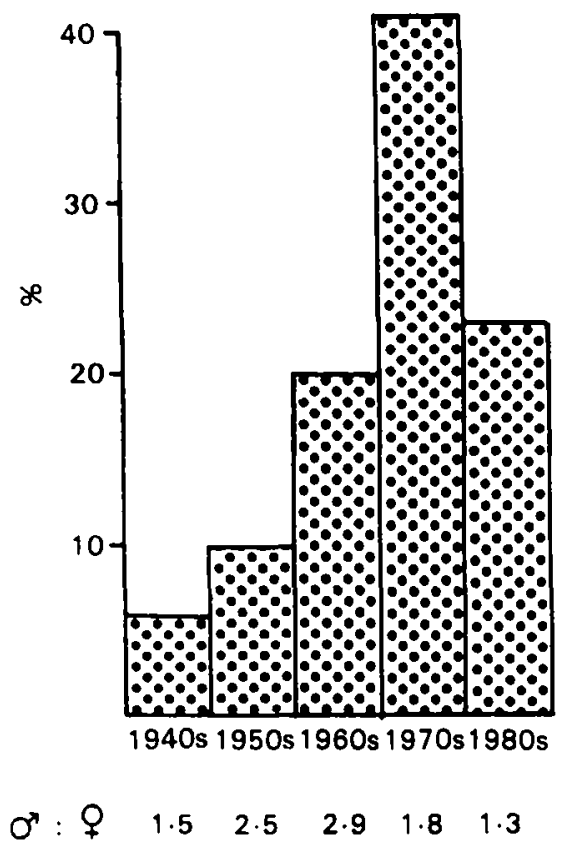

Fig. 3. Questionnaire respondents by year of joining the Nutrition Society. Thus 1940 to 1949 are grouped as the $1940 \mathrm{~s}$, $195^{\circ}$ to 1959 as $195^{\circ}$, etc. The 1980 s category includes members joining between 1980 and 1984 . The ratio of men:women joining in each decade is also shown.

Table 1. Where our questionnaire respondents live

Country of residence No. of members $\begin{gathered}\text { No. of } \\ \text { countries } \\ \text { mentioned }\end{gathered}$

UK (all England, plus some

745

I

Scotland, Wales and Northern

Ireland)

Scotland

Irish Republic

Northern Ireland

Wales

All UK

$\begin{array}{rr}124 & 1 \\ 23 & 1 \\ 13 & 1 \\ 6 & 1 \\ 911 & 5\end{array}$

Other European

North America (US + Canada)

Australasia

Middle East

Far East

Africa

Central + South America

All overseas

76

97

69

25

26

17

17

327

Total

$123^{8}$

15
2
4
11
12
12
6
62
67


Table 2. Nationality of questionnaire respondents

$\begin{array}{lcc}\text { Nationality } & \text { No. of members } & \begin{array}{c}\text { No. of } \\ \text { nationalities } \\ \text { mentioned }\end{array} \\ \text { British } & \mathbf{8 8 5} & \text { I } \\ \text { Irish } & 25 & I \\ \text { Scottish } & 11 & \text { II } \\ \text { Welsh } & 3 & 1 \\ \text { British mixed } & 19 & 9 \\ \text { All British } & 943 & 13 \\ \text { Other European } & 86 & \\ \text { North American } & 67 & 15 \\ \text { Australasian } & 53 & 2 \\ \text { Far Eastern } & 28 & 2 \\ \text { Middle Eastern } & 24 & 9 \\ \text { African } & 19 & 9 \\ \text { Central + South American } & 14 & 9 \\ \text { All non-British } & 291 & 73 \\ \text { Total } & 1234 & 66\end{array}$

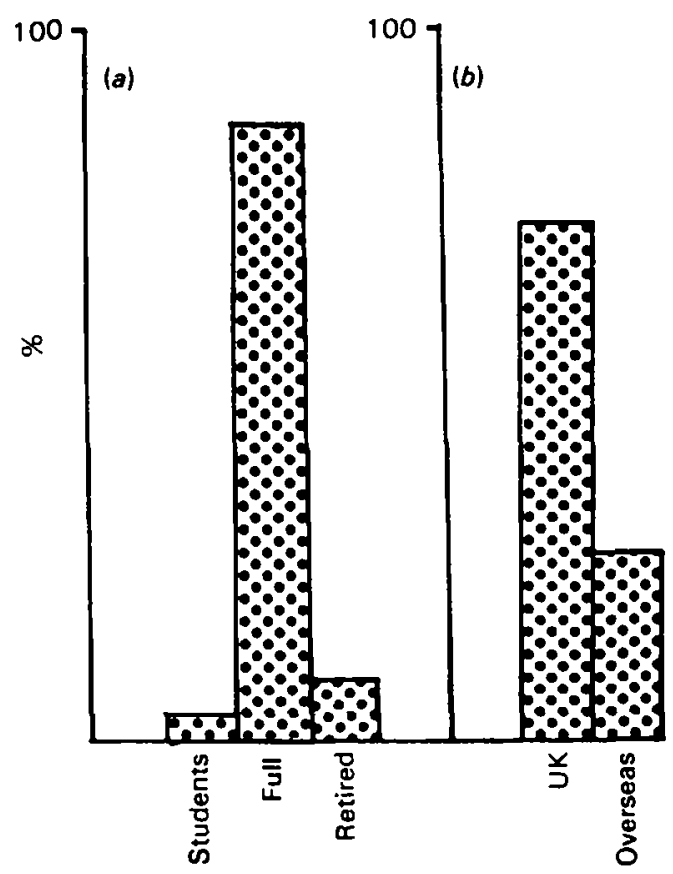

Fig. 4. Questionnaire respondents by ( $a$ ) membership status and (b) country of residence. 
Table 2 shows the nationality of our members: $76 \%$ of them are British, with $2 \%$ of these people having dual nationality-usually that of Britain and a Commonwealth country. It was interesting to note that eleven members insisted that their nationality was Scottish and that three members insisted on Welsh nationality. All English members on the other hand seemed content to call themselves British. One female member (who happens to be personally known to us) insisted that she was a 'multinational' since she has the right to call herself either Swiss, British, or Australian whenever the occasion arises!

Fig. 4 shows the membership status of those who responded to the questionnaire. The proportions of full, student and retired members are virtually exactly as they were reported at the ${ }_{19} 8_{5}$ AGM and this fact helps to confirm our belief that the questionnaire response was representative of the total membership. We asked members to record whether they had ever played an active role in the running of the Society and were somewhat alarmed to find that over $85 \%$ had been 'passive' members of the Society. This rather sorry state of affairs has already been communicated to the Nutrition Society Council, Programmes Committee and Editors of the Journals and all have promised to make a positive effort to get some 'new blood' into the active nucleus of the Society.

\section{What jobs do we do?}

The question relating to the jobs of members ( $Q$. ro) was certainly the most difficult one for us to compile and seemingly the most difficult for members to answer! We realized that we could not give a never-ending list of job categories that members might fit into, and we wanted to keep the list as short as possible so that we could analyse the answers to the second half of the questionnaire by the job of

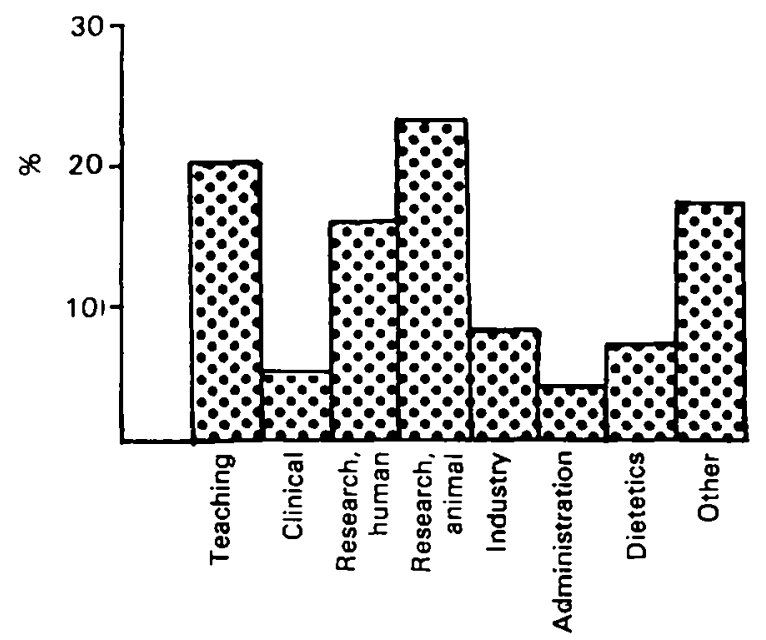

Fig. 5. Questionnaire respondents by present job category. 


\section{Vol. 45}

the respondent. We were prepared, then, for a lot of members to categorize their jobs as 'other' and you will see from Fig. 5 that this was the case. A lot of members also told us that they could not possibly categorize their jobs into a single category and so we had to put these people into the 'other' category too. Apart from these inherent problems, Fig. 5 shows that the greatest proportion of members categorize their jobs as animal-orientated research, with teaching and human-orientated research coming closely behind.

Question Io(b) asked about the permanency of the job: $80 \%$ of members had permanent jobs, I6\% of them didn't (see Fig. 6). Amongst men, there were $85 \%$ with permanent jobs, but only $71 \%$ of the women had tenured status.

\section{What qualifications do we have?}

Question 7 asked members to list their formal qualifications. We were expecting a reasonable variety of degrees and diplomas to emerge in response to this question but we were not prepared for a list of nearly 200 . Table 3 shows just those degrees which were mentioned at least ten times. You can see that about $58 \%$ of members are Bachelors of Science with only a slightly smaller number having doctorates. It is probable but not certain because of the way the analysis was done, that most of the BSc's are PhD's as well. Medical degrees were very prominent, but note the number of different qualifications that we have combined in this category. $A$ large

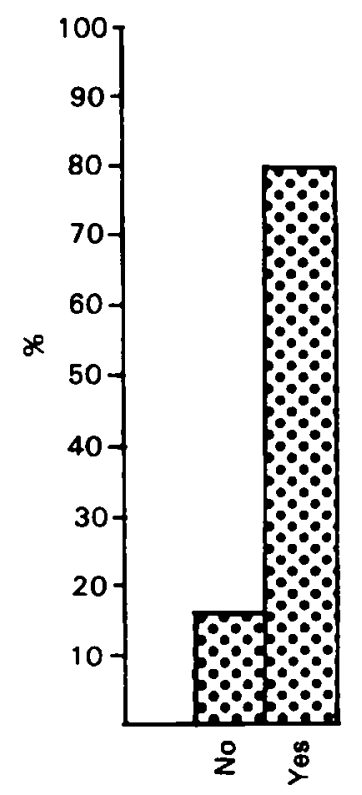

Fig. 6. Response to Q. Io(b): 'Is your present job permanent?' 


\section{Table 3. Qualifications of questionnaire respondents}

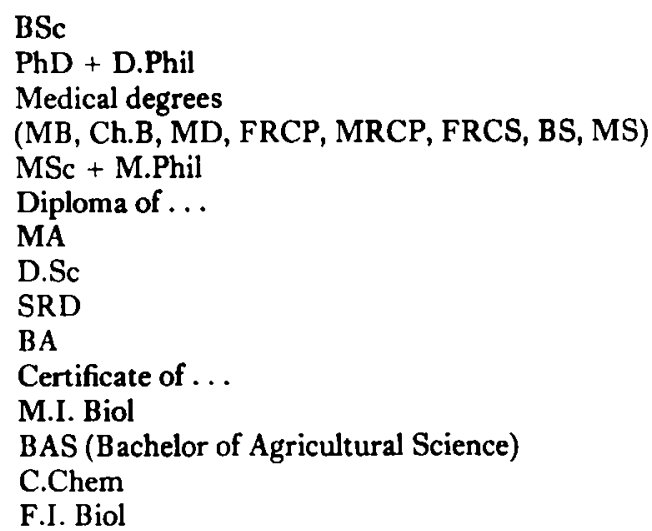

No. of times mentioned

727
661
300

264
178
66
64
48
44
31
23
15
11
11

number of people held diplomas and most of these were, not surprisingly, diplomas in Nutrition. Also note that the Nutrition Society has sixty-four members who are Doctors of Science and, although they have not been included in Table 3 , there are six Fellows of the Royal Society among our numbers. Finally, there were at least I00 qualifications, each held by single members, which were completely unknown to us. What, for instance, is P.A.S.C., R.P.D.T. and, even more curious, W.C.?

\section{What are our interests in nutrition?}

The 1257 respondents to the questionnaire used 2001 key words to describe their interests - a nutritional space odyssey! Not surprisingly the favourite word was 'nutrition', quoted I 67 times. This, and related words 'nutrient', 'dietary', 'food', 'feed', 'feeding' and 'metabolism' appeared 2 I 54 times in the replies. Aside from these general references to nutrition, the word mentioned most often was 'ruminant' (254). The particular references to 'man' (including words like 'infant') totalled 372 , although a prime interest in man will be implicit in many responses.

The runner-up in the most popular animal stakes was the pig (39) followed by a wide variety of animals including Australopithecus* (I), buffalo ( 1 ) and crustaceans, or as one member put it 'anything from rats to racehorses'.

Disease and health received equal attention ( $110, \mathrm{IO}_{4}$ respectively) 'obesity' was the 'disease' cited most (90), followed by 'diabetes' (47) and 'cancer' (37). Again the varied replies reflect the wide range of interest of the membership from atherosclerosis (12) to vomiting (1). 'Diarrhoea' appeared as three different key words according to the spelling!

The top five individual food components were protein (184), energy (171), vitamins (97) and fibre (5I) followed by a range of items including individual foods such as the humble sausage ( $\mathrm{I}$ ).

-During the preparation of this manuscript, we have been informed that this is a man not an animal. Sorry! 


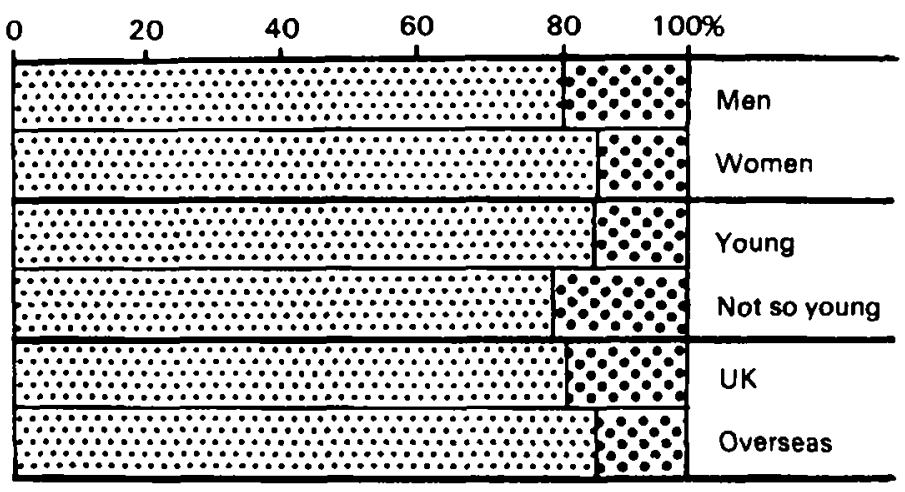

Fig. 7. Response to Q. 11 : 'Would you find it useful if the Nutrition Society produced an updated list of members which included their fields of interest?' $\mathrm{O}$, , Yes, $\square$, no, young (under 45), not so young ( 45 and over); UK and overseas refer to country of residence.

The place or type of work, or both, appeared in the key words, as follows; 'education' (139), 'clinical' + 'hospital' (85), 'community' + 'social' (60), 'research' (54).

It would appear that most members are interested in nutrition in general and how food is metabolized in the body. At least $20 \%$ of members are particularly interested in ruminants. The analysis of key words will probably form a basis for designing a tick chart of fifty key words to define the interests of members more precisely since it was obvious from the answers to $Q$. II that a very high proportion of respondents would find an updated list of members useful, especially if it included their fields of interest (see Fig. 7).

\section{Do we want joint meetings with other societies?}

Finally, in the first section of the questionnaire we asked members whether they thought that the Society should arrange more joint meetings with other Societies. The majority of members $(78 \%)$ were in favour of this and 685 members made suggestions as to which Societies would be suitable. These have been listed and passed to the Programmes Committee for use in the planning of future symposia.

\section{What are our views on important issues in the 1980s?}

(i) Analysis procedure. For all the questions in the second section of the questionnaire, members were asked to record their agreement or disagreement using a five-point scale:

$\begin{array}{lll}\text { Yes, I agree strongly } & \text { (A) } & \text { No, I disagree } \\ \text { Yes, I agree } & \text { (B) } & \text { No, I disagree strongly } \\ \text { I have no definite opinion } & \text { (C) }\end{array}$


Most members seemed reasonably happy to confine themselves to these five categories although one wit decided to invent a sixth category ' $F$ ' which he or she defined as 'Yes, possibly in some circumstances'!

The use of this scale has allowed us not only to analyse the answers to the questions in terms of the percentage saying (A) or (B), etc. but also to calculate a 'mean opinion score' to make it easier to compare responses for different subgroups of members. Thus, $A$ responses have been given a score of $+2, B$ reponses a score of $+I, C$ responses a score of $0, D$ responses a score of $-I$ and $E$ responses a score of $\mathbf{- 2}$. Therefore a mean opinion score of +2 would indicate total agreement and a mean opinion score of -2 would show total disagreement. A mean score of $o$ indicates overall neutrality. The extent of divergence of opinion is reflected in the standard deviation of the mean opinion score.

\section{MEMBERS' COMMENTS}

"The Society can no longer justify distancing itself from debating controversial issues. In this event the middle ground will be taken over by "cranks and barrow pushers:"

\section{"The Society should seek to estabitsh itself as the ultimate authority on matters of nutrition in this country instead of leaving it to the present ragbag of cranks and zealots and purveyors of nutritional information."}

\section{"He who doesn't contest, consents."}

"Some members have no other forum on which to express a view and as professional nutritionists they are horrified at what the public is being told. It is this gap that I feel the Society should try to fill." (ii) Should the Society provide some type of forum for discussion of nutritional controversies? Fig. 8 shows that the vast majority of questionnaire respondents agreed that the Society should provide a forum (i.e. they gave an A or B response to Q. 15), with about half of them being strongly in favour (i.e. an $A$ response). The mean opinion score for this

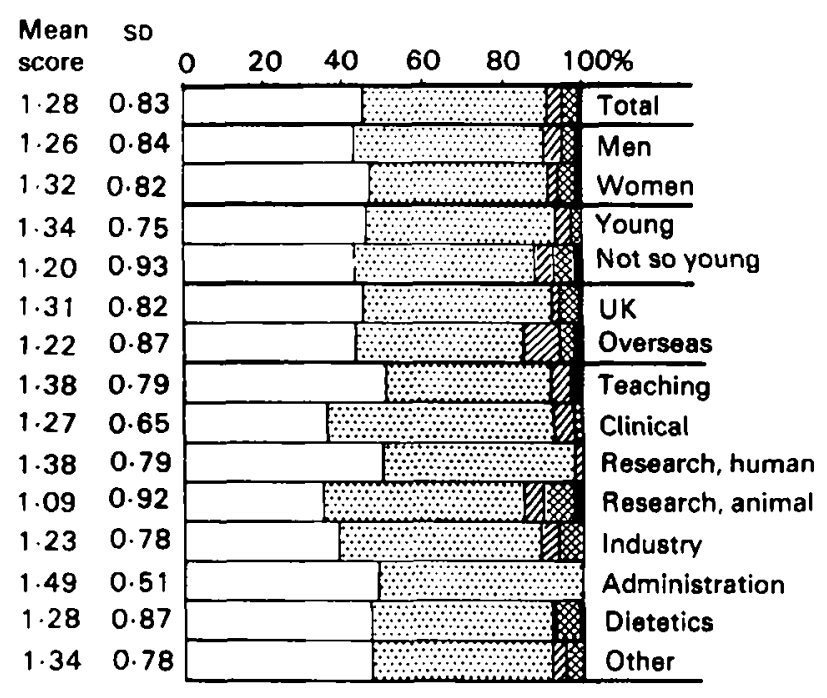

Fig. 8. Response to Q. 15: "The Nutrition Society should provide some type of forum for the discussion of nutritional controversies.' Questionnaire respondents' agreement or disagreement with this statement expressed in terms of percentage stating strong agreement $(\square, A)$, agreement (界, B), neutrality, ( $\mathrm{O}$ C), disagreement $(\mathrm{D}, \mathrm{D})$, strong disagreement $(\mathbf{E}, \mathrm{E})$. Opinion scores (mean and standard deviations) are also given for each subgroup. 
MEMBERS' COMMENTS

"We do have a duty to indulge in debate and to educate and inform the public where possible, but the temptation to embark upon producing statements which might be seen as some sort of truth must be sternly and totally resisted."

\footnotetext{
"Controversy attracts a small but unwelcome number of publicity seekers and these could exert an undue infiuence on the Society."

"History is littered with examples of the unwisdom of linking the search for scientific truth with the pottical tmplications of such truth, from Socrates to Gallieo and Darwin. Shoemaker stick to your last!"
}

"Most of the controversies are in the field of human nutrition perhaps because the standard of some of the scientific work in the area of human nutrition does not match the standard set by animal nutritionists!"

"The role of growth promoters in Uvestock and whether they should be banned or their use extended is an example of current controversy of importance in animal nutrition especially in view of recent $E E C$ statements."

"A formal debate followed by an open discussion would be the most appropriate."

"Whatever format is selected it should be one that encourages objective analysis of the problem. It is most important to avoid the type of debate/discussion that generates emotion and leads to confrontation." question was I-28. Fig. 8 also shows that women were slightly more in favour of a forum than men and that those in the 'young' category were slightly more in favour than those in the 'not so young' category. In fact, 'young women' showed a mean opinion score of $\mathrm{I} \cdot 40$ for this statement. There was slightly more enthusiasm amongst UK members compared with overseas members (mean opinion scores of $I \cdot 3 I$ and $I \cdot 22$ respectively) but the greatest divergence of opinion to this question was seen when the replies were divided according to the job of the respondent. Those who classified their jobs as administrators agreed 'to a man' (or womanl) that we should provide some type of forum for the discussion of nutritional controversies (mean opinion score 1 -49) and the clinicians, dietitians and human nutrition researchers showed very little disagreement with the idea. Those who showed most disagreement with the idea (although this only amounted to $10 \%$ of them) were those members researching into animal nutrition. Maybe this reflects the fact that 'ruminant controversies' are probably scientific whilst 'human controversies' are more likely to be political.

When it came to the question of how the Nutrition Society should discuss nutritional controversies, there was a much greater divergence of opinion. Table 4 shows some mean opinion scores for the questions which relate to this issue. The idea of a formal debate was not well received (Q. I6) and the mean opinion score, very close to 0 , reflected a large neutral response $(35 \%)$ with roughly equal numbers of people agreeing $(30 \%)$ and disagreeing $(36 \%)$ with the idea. There was much greater enthusiasm for the idea of open discussions (Q. I 7$)$ as indicated by the score of 0.67 ; in fact only $10 \%$ of those answering this question disagreed with this idea whilst $13 \%$ were strongly in favour of it. There was, however, greater general enthusiasm for the idea of forums to discuss nutritional controversies 


\section{MEMBERS' COMMENTS}

"The forum should not leave the issue hanging in the air-a Society view should be reached if possible."

"We should have the courage to take a definittve stand, one way or the other. It is crucially important that the Society should be able to come up with a definitive viewpoint at the end of the debate."

"Members of the Society could also be encouraged to stand by the agreed viewpoint so that a conststent coherent front is kept."

"In no way should there be a Society view. We are a scientific Soclety and as such our members are able to formulate their own opinions and express them in their own indtvidual way. Any other way opens up the Society to pressure groups, etc."

"Science does not operate on democratic principles. Indeed it is common experience that the majority of scientists are wrong and $a$ minority, sometimes of one, proves to be right. The awarding of prizes frequently refiects this fact."

"Neither formal debate nor open discussion is bikely to be of much avall without proper, well organized preparation by a Working Party."

"The Working Party could prepare drafi reports on controversial issues which could form the basis for discussion at the forum. These should be circulated to members before the meeting."
Table 4. How to discuss nutritional controversies

$\begin{array}{lll}\begin{array}{l}\text { A forum should take the form of a } \\ \text { formal debate }\end{array} & -0.05 & 0.94 \\ \begin{array}{l}\text { A forum should take the form of an } \\ \text { open discussion }\end{array} & 0.67 & 0.85 \\ \begin{array}{l}\text { A forum should produce a resolution } \\ \text { or arrive at a policy decision if }\end{array} & 0.74 & \mathbf{1} \cdot 03 \\ \begin{array}{l}\text { appropriate } \\ \begin{array}{l}\text { Working parties should be set up to } \\ \text { discuss and report on certain areas of }\end{array}\end{array} & \mathbf{1} \cdot 29 & 0.75 \\ \begin{array}{l}\text { nutritional controversy } \\ \begin{array}{l}\text { The Nutrition Society should discuss } \\ \text { and produce public definitions for } \\ \text { certain words related to nutrition }\end{array}\end{array} & \mathbf{1} \cdot 09 & 0.81 \\ \end{array}$

arriving at a policy decision or producing a resolution if appropriate (Q. 18$)$. In all $73 \%$ of members answering this question were in agreement with the idea.

Another idea which was met with enthusiasm was the idea that the Nutrition Society should discuss and produce public definitions for certain words connected with nutrition (Q. 22); $83 \%$ of members agreed with this suggestion. There is something rather amusing about this since the Working Party set up to review careers in nutrition has had great difficulty in agreeing a definition of the word 'nutritionist'!

Greater still was the tremendous support for the idea of setting up Working Parties to discuss and report on areas of nutritional controversy with $93 \%$ of members agreeing that this was a good idea (Q. 19).

Media coverage of the Society's meetings was covered by $Q$. 20 and 21 . At present the programme for the Society's regular symposia carries the words 'Members are reminded that meetings of the Society are private, visitors must be introduced personally and unauthorized accounts of the proceedings must not be communicated to the press'. Table 5 shows that 
MEMBERS' COMMENTS

"Media coverage could improve publtc awareness of the continuing debate in academic ctrcles. Too often in the past the layman has been presented with 'black and white' alternatives. This has led to apparent 'reversals' of opinion which call into question the validity of nutrition information generally."

"The media exerts a powerful infuence on publlc opinion. I suppose we should learn to live with it and exploit it when there is a clear point to make."

"We should issue selected, prediscussed press releases."

"The Society should employ or seek funds to employ its own Public Relations Officer."

"The Public Relations Officer should be a scientist trained to conmunicate with the media and should be able to create a good working relationshtp with the media and be a focus where the media can obtain an informal view."

"A Public Relations Officer could highlight spectic areas of research and encourage the generation of finance, particularly from industry, to support such work."

"The Soctety should not provide a stage for its limelight seekers to dance in front of the public."

"Media coverage of meetings could, and probably would, be disastrous. Reporters, even the best, tend to setze on 'man bites dog' ttems."
Table 5. Media coverage

At present, the Society's regular symposia receive no media coverage; Opinion score $\overbrace{\text { Mean }}^{\text {SD }}$ this policy should change

If the Society did organize some type of forum on nutritional controversies, media coverage should be considered

$0.69 \quad 1.00$

there is a certain amount of feeling that this policy should change. Certainly there were a greater proportion of members agreeing with the idea of change ( $48 \%$ ) compared with those disagreeing $(27 \%)$. However, if the Nutrition Society were to hold some type of forum with the specific purpose of discussing nutritional controversies, then there would seem to be much greater enthusiasm for inviting the press along to report the meetings; $73 \%$ of respondents agreed with this idea although only $15 \%$ of them were in strong agreement.

(iii) Should the Nutrition Society do more for its overseas members? Table I gives details on

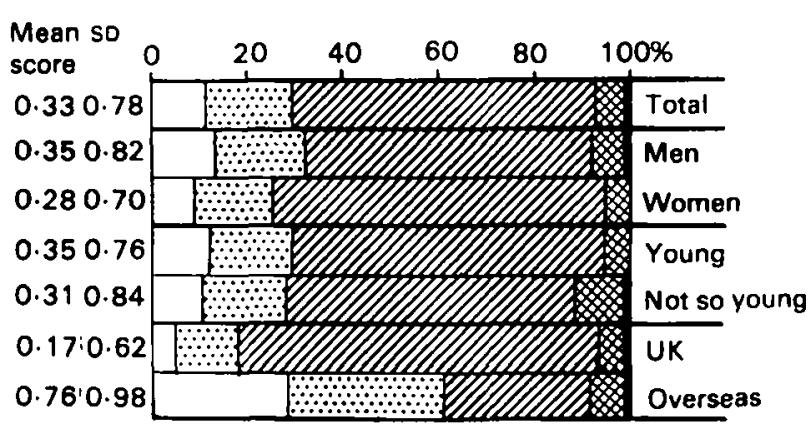

Fig. 9. Response to Q. 24: "The Nutrition Society could do more for its overseas members.' Questionnaire respondents' agreement or disagreement with this statement expressed in terms of percentage stating strong agreement $(\square, A)$, agreement $($ 国, B), neutrality $(\mathbb{B}, C)$, disagreement $(B, D)$, strong disagreement $(\square, E)$. Opinion scores (mean and standard deviations) are also given for each subgroup. 
MEMBERS' COMMENTS

"I am appreciative of the links I have with the Society through my membership."

"I appreciate the information sent to me even if the delay in receiving communications means that the meetings are over before I receive the programme and abstracts."

\footnotetext{
"Indication should be made of how recommendations for the Developed World should be modified for underdeveloped countries."
}

"A meeting could be held to attempt to reconcile differences in recommended dally allowances."

\footnotetext{
"We should have joint European meetings with other European nutrittion societies and closer ties with the Federation of European Nutrition Societies."

"The Nutrition Saciety could keep a register of overseas members intending to visit the UK and their fields of interest. This might be circulated with notices of meetings or in Nutrition News and Notes."
}

\section{"The Nutrition Society should provide publications free or at a discounted rate to developing countries, including those who have difficulty in obtaining Western currency."}

"The Society could keep a register of active research being conducted by members so that $U K$ and overseas members with similar interests can make contact with each other."

"The Society should be careful not to dissipate its energies in the bottomless pit of international activities!" the countries of residence of members and shows that over a quarter of our members live outside the UK. Fig. 9 shows the response to Q. 24 in which we invited comments on how well or otherwise we look after these overseas members. On the whole, the questionnaire respondents did not feel strongly about this issue with $63 \%$ of them recording a neutral (C) response; the mean opinion score worked out at $0 \cdot 33$. There were only small differences between the sexes and age groups but, quite predictably, division by country of residence showed that overseas members were less satisfied with what they get from the Nutrition Society than UK members. However, it is interesting to see that only $28 \%$ of overseas members felt strongly about this issue and that $8 \%$ of them actually disagreed with the statement.

Questions 25 and 26 attempted to explore what, if anything, could be done to improve the 'lot' of overseas members. Table 6 shows that there was greater support for inviting more overseas speakers to meetings than there was for holding more symposia on 'overseas' problems. Not surprisingly, overseas members were more enthusiastic than UK members on both counts.

(iv) Should the Nutrition Society do more to improve employment prospects for those trained in nutrition? The issue of employment

Table 6. What can be done for overseas members?

Money allowing, the Nutrition Society should invite more overseas speakers to its symposia

The Nutrition Society should hold more of its symposia on 'overseas' problems

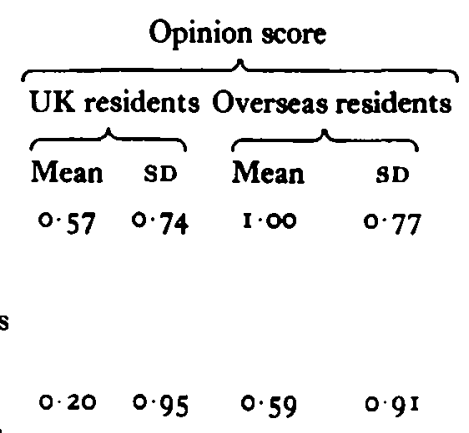




\section{MEMBERS' COMMENTS}

"We need to make more effort to improve both the employment prospects and the status of those trained in nutritional science, in order that there is recognition of the degree of specialization involved and that nutrition as a subject is given the consideration it deserves."

"There is no 'forum' for advertising posts in nutrition. Perhaps jobs could be advertised in Nutrition News and Notes, or the British Journal of Nutrition."

"There are still many unqualified people dabbling in nutrition, often exploiting the public with unscientific claims, for considerable financial gain."

"Nobody is going to offer careers wholesale to a group that can be diluted with charlatans."

"I cannot see how the Society can be involved in problems of employment of nutritionists.

Unemployment is a political problem and individual members should seek to infiuence political polictes in their own individual ways."
Table 7. The Nutrition Society should attempt to improve employment prospects for those trained in nutrition

\begin{tabular}{lcc} 
& Opinion score \\
\cline { 2 - 3 } Mean & SD \\
Men & 0.79 & 0.97 \\
Women & 0.74 & 1.00 \\
Young (under 45) & 0.90 & 0.91 \\
Not so young (45 and over) & 0.99 & 0.90 \\
UK members & 0.52 & 1.01 \\
Overseas members & 0.82 & 0.97 \\
& 0.74 & 0.97
\end{tabular}

prospects for those trained in nutrition was covered by $Q .27$ and 28 . The response to $Q .27$ is shown in Table 7. The overall mean opinion score of 0.79 reflects $67 \%$ agreement, $22 \%$ neutrality and $11 \%$ disagreement with the idea

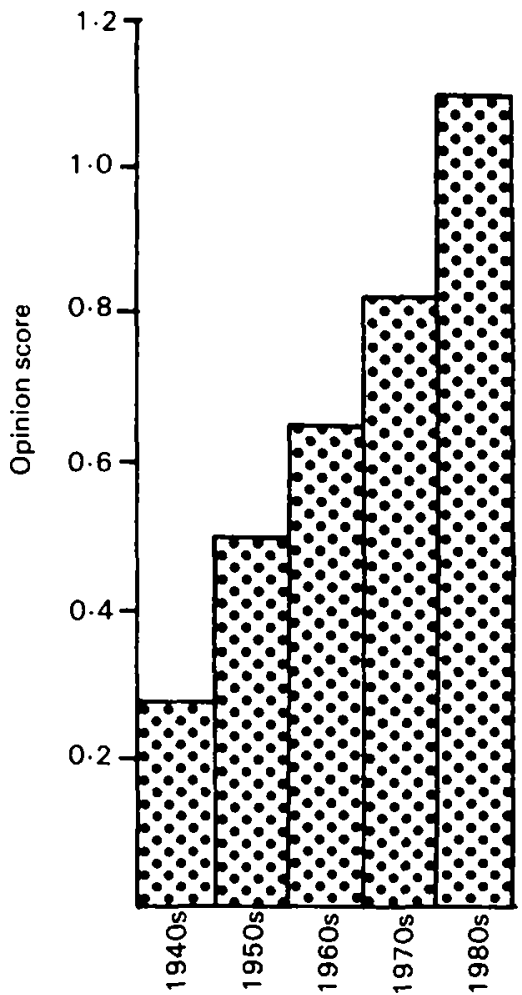

Fig. I0. Response to Q. 27: "The Nutrition Society should attempt to improve employment prospects for those trained in Nutrition.' Questionnaire respondents' agreement or disagreement with this statement expressed as the mean opinion score of subgroups divided according to length of membership of the Nutrition Society. 


\section{MEMBERS' COMMENTS}

"We should go the whole hog and create a Royal College of Nutrition."

"I am beginning to be aware of the need to protect the name 'nutritionist'. Confine the word 'nutritionist' to those who actually have qualifications in the subject."

"Anything which will improve the status of nutrition as a science is to be encouraged. A recognized qualification would serve to outlaw the 'lunatic fringe' and minimize the danger of confusing the layman."

\section{"With impending regulations relating to food quality/content/ value, etc. on the horizon, I would have thought that the future for employment) was rosier in the field of nutritional science than in certain other areas at present. I feel it would be opportune for the Nutrition Society to capitalize in this growing area of public interest and scrutiny by launching a professional body."}

\footnotetext{
"Registration of nutritionists is imperative at the moment anyone can call him/herself a nutritionist and gain public attention, including, sadly, many conventional scientists qualified in related areas (e.g. animal nutrition and even medicine), but who are not directly qualified in human nutrition."

"As a State Regtstered Dietitian I
already belong to a professional
organization, The British Dietetic
Association, but feel that here again
status needs to be improved. I also
feel that there is a need for a body of
professional standing for those
trained in nutritional sctence and not
necessarily dietetics."
}

that the Nutrition Society could do more to improve employment prospects. Most enthusiasm was from women and from the younger members. In fact, the mean opinion score of young women was 1.07 . The most interesting part of the analysis of the response to this particular statement emerged when members were classified by their date of joining the Nutrition Society. Fig. Io shows how the mean opinion score increased in a stepwise fashion as the date of joining the Nutrition Society approached the present day. In other words, the most longstanding members are the ones least concerned with employment prospects. A case, maybe, of 'I'm all right, Jack'?

In Q. 28, it was suggested that there is a need for a professional organization to give status to those trained in nutritional science. Fig. II summarizes the responses to this suggestion and shows that a wide spread of opinions exists.

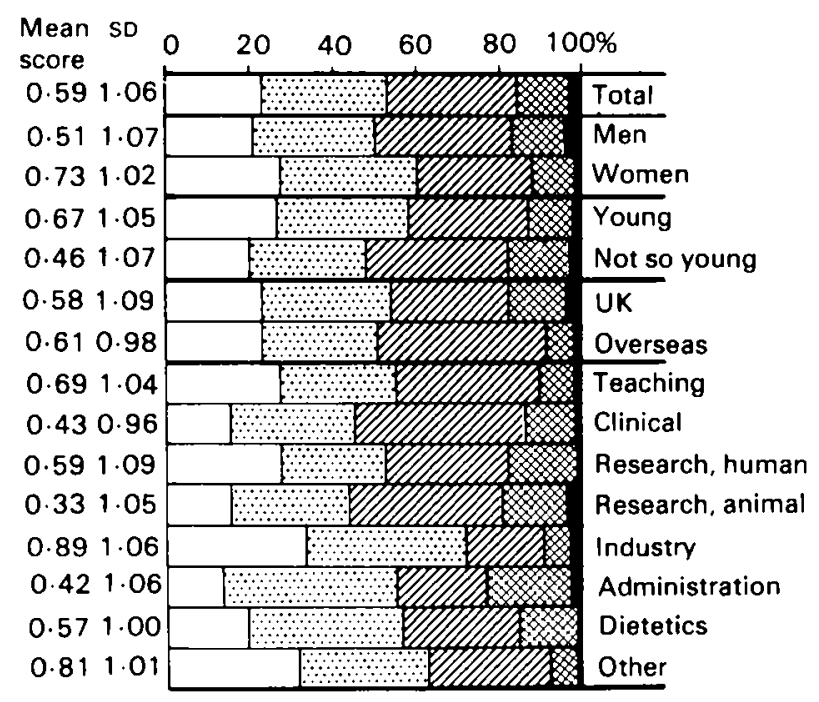

Fig. II. Response to $Q$. 28: 'There is a need for a professional organization to give status to those trained in nutritional science.' Questionnaire respondents' agreement or disagreement with this statement expressed in terms of percentage stating strong agreement $(\square, A)$,

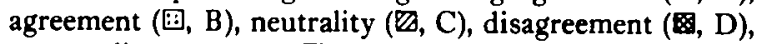
strong disagreement $(\boldsymbol{\square}, \mathrm{E})$. Opinion scores (mean and standard deviations) are also given for each subgroup. 
MEMBERS' COMMENTS

"I regard nutrition as an area of science that overlaps biochemistry, physiology, medicine and veterinary science, rather than a discipline in its own right."

"Nutrition is too varied to be covered by a single professional body."

"The Society was set up as a learned Society and that is how it should remain!"
"Questionnatres do not solve problems!"
Overall, the suggestion gained a mean opinion score of 0.59 ; this reflected $23 \%$ strong agreement, $30 \%$ agreement, $31 \%$ neutrality and $16 \%$ disagreement. As usual, women were more in favour of a professional organization than men and young members were more in favour than older members. An interesting difference was noted when the questionnaire respondents were divided according to their job. Yet again, members engaged in animal-orientated research were least bothered about the need for a professional organization, whilst those members working in industry were most aware of the need. It is also interesting that the group whose job is classified as 'other' (i.e. they do something which cannot be easily classified into one of the seven categories or they do jobs which cut across several categories) are also quite strongly in favour of a professional organization $(62 \%$ of them agreed with the idea compared with only $43 \%$ of the animal researchers.) Perhaps this need for increased professional status indicates that the 'others' tend to work in areas where they come up against colleagues, such as accountants, who have their own professional organization. Alternatively, the fact that they work in more than one field may make them more conscious of the need for a unifying professional organization.

\section{How reliable is questionnaire analysis?}

The analysis of the questionnaire has assumed, reasonably enough, that the replies mean something. Fortunately, due to a curious combination of circumstances, this assumption could be tested. Those members who did not respond to the first questionnaire mailing were sent it again, and in eight cases this resulted in two questionnaires being received from the same member. It should be emphasized that this was not planned, and we are sorry that the people involved were put to some inconvenience. On the other hand we were glad, as it allowed us to validate the questionnaire formally. 


\section{Table 8. Duplicate answers to eight questionnaires}

\begin{tabular}{|c|c|c|c|c|c|c|c|c|c|}
\hline \multirow[b]{2}{*}{ Question } & \multicolumn{8}{|c|}{ Subjects } & \multirow{2}{*}{$\begin{array}{l}\text { Question } \\
\text { discordance }\end{array}$} \\
\hline & I & 2 & 3 & 4 & 5 & 6 & 7 & 8 & \\
\hline 15 & B B & B A & $\mathrm{BA}$ & $\mathrm{D}^{\bullet} \mathrm{B}$ & $B^{\bullet} \mathrm{D}$ & $D \bullet B$ & $C D$ & $\mathrm{~A} A$ & 6 \\
\hline I9 & B B & $\mathrm{B}$ A & $\mathrm{A} A$ & B B & B B & B B & B B & B A & 2 \\
\hline 20 & C D & $\mathrm{DC}$ & $C D$ & $B \bullet D$ & $E^{\star} \mathrm{C}$ & DE & A B & $\mathrm{C} \mathrm{C}$ & 7 \\
\hline $2 \mathrm{I}$ & B B & $\mathrm{DC}$ & $\mathrm{D} \bullet \mathrm{B}$ & $B \bullet E$ & $\mathrm{E} * \mathrm{~B}$ & $\overline{\mathrm{D}} \overline{\mathrm{D}}$ & B C & $\mathrm{C} \mathrm{C}$ & 5 \\
\hline 22 & B B & B A & B B & $A \mathbf{A}$ & $\mathrm{C}^{\bullet} \mathrm{A}$ & B B & C B & A B & 4 \\
\hline 23 & C C & $\mathrm{C} \mathrm{C}$ & $\mathrm{C} \mathrm{C}$ & $\mathrm{C} \mathrm{C}$ & $\mathrm{C} \mathrm{C}$ & $\mathrm{C} C$ & D D & $\mathrm{C} \mathrm{C}$ & 0 \\
\hline 24 & C C & $\mathrm{C} \mathrm{C}$ & C C & C C & C C & $\mathrm{C} \mathrm{C}$ & C C & $\mathrm{C} \mathrm{C}$ & 0 \\
\hline 25 & B B & B B & C C & C B & C B & B B & B A & B C & 4 \\
\hline 26 & D C & B B & B B & $\mathrm{B}^{\bullet} \mathrm{D}$ & D C & C C & C D & B C & 5 \\
\hline 27 & $\mathrm{C} B$ & $C B$ & B B & B B & $C B$ & B B & $A B$ & B B & 4 \\
\hline 28 & B B & B B & $A B$ & D C & $D^{\bullet} B$ & $C^{\bullet} E$ & B A & B C & 6 \\
\hline $\begin{array}{c}\text { Subject } \\
\text { discordance }\end{array}$ & 3 & 6 & 4 & 6 & 8 & 3 & 8 & 5 & 43 \\
\hline
\end{tabular}

-Disagreement in response by more than I point.

The comparison of replies was restricted to Q. 15 and 19 to 28 , a total of eleven questions. Table 8 gives the eighty-eight pairs of replies from the eight members, and those showing a disagreement of more than I point are marked with an asterisk. Also shown are discordance scores, by subject and by question number, indicating the number of questions answered differently on the two occasions.

Several points emerge from the Table. Of the eighty-eight comparisons, forty-five showed complete agreement, thirty-one had a disagreement of I point (e.g. $\mathrm{B} v . \mathrm{C}$ ), ten a disagreement of 2 points (eight of them $\mathrm{B} v . \mathrm{D}$ ), and just two a disagreement of 3 points (both $B v$. E, and both in Q. 2I). Thus half of the questions were answered consistently, interspersed with occasional large shifts of opinion. Certain individual questions were more variable than others, e.g. Q. 20, media coverage of symposia, where only one of the eight members gave the same answer both times; or Q. 15, a forum for nutritional controversies, where only two out of the eight were consistent. At the other extreme, Q. 23 and 24 on other countries and overseas members, achieved total agreement. This slightly alarming picture of inconsistency is actually not as bad as it seems since most of the disagreement is by only I point on the scale. If this is viewed as a relatively small shift of opinion, then seventy-six of the eighty-eight responses are acceptably consistent. Even if the level of agreement were substantially worse, it would not necessarily invalidate the conclusions that we have drawn. The only grounds for doubting them would be if the (apparently) random variation was in fact systematic, for example if the shift in opinion from $B$ to $E$ on $Q .21$ represented the effect of having more time to think about the question. Unfortunately we did not record the order in which questionnaires were returned, so we cannot test this. 
On the whole the questionnaire appears to measure the opinion of members well (always assuming that these eight are representative of the Society as a whole), so we feel confident in presenting them for consideration by the Society.

\section{Conclusions}

One of the first things to strike us when we started to analyse the questionnaires was the enormous enthusiasm that members have for their Society. This was not only reflected in the good response rate that we achieved, but also in the high proportion of people who were prepared to give their additional comments, sometimes at great length. We have attempted to show some of these here because we feel that they are every bit as informative as the statistical analysis that forms the bulk of this paper. We are very grateful to all members who took time and trouble to write their comments and assure them that they will all be read exhaustively by those whose job it is to run the Society.

The information that members gave in Section One of the questionnaire has been useful in its own right to give us a better idea of the composition of our membership but it has also enabled us to analyse members' responses to Section Two in more detail. There were three main issues being discussed in this section and each of these was very different from the others. It was therefore quite surprising that, on all three issues, a consistent picture emerged of the type of member who usually wanted to see changes made and the type of member who usually wanted to see the Society stay as it is. The 'identikit' picture of the slightly radical member would be: a young, female, newish member of the Society, probably with an untenured job in teaching or human nutrition research. On the other hand, the 'identikit' picture of the more conservative member would be: a 'not so young', male, longstanding member of the Society with a permanent post in animal nutrition research.

What lessons can be drawn from all this information? First, we have realized that many members with original ideas exist at grass-roots level, none of whom have ever been involved in any way in running the Nutrition Society. It is perhaps inherent in the way that we elect our Council that one must reach a certain level of maturity and scientific standing to be nominated. Let us hope that more effort is made in future years to elect younger people to Council and to Committees and that more effort is made to expand the organization of the Society in such a way that younger people are allowed to voice their opinions earlier in their careers as nutritionists. In the meantime, of course, the correspondence columns of Nutrition News and Notes are open to all!

Next, members have given us a clear mandate to explore two practical suggestions. The Programmes Committee will peruse the list of suggestions for joint meetings with other Societies and will act accordingly. Producing a list of members which includes their fields of interest in Nutrition will be costly, take time to organize and will require quite a lot of work to keep it up to date once it is done. However, now we know that this idea has very good support from members, we will pursue the idea with speed and enthusiasm. 
Finally, it is clear that most members think that the Nutrition Society should provide some type of forum for the discussion of nutritional controversies although it is also clear that members feel that we should not in any way jeopardize our reputation as a scientific society for this. Open discussions seem to be preferred, in general, to formal debates and it was with this in mind that we introduced the open discussions on 'Salt' in May 1985 and on 'Famine' in May 1986.

On the question of overseas members, it is comforting that only just over a quarter of them feel strongly that the Nutrition Society could do more for them. Perhaps the rest take the realistic approach that membership of the Nutrition Society affords a cost-effective method of keeping in touch with nutritionists in the UK and elsewhere and at the same time allows them to buy the Society's journals at special rates. However, we shall try to invite overseas speakers to future symposia whenever appropriate and possible, providing the budget will allow it.

The concern for the improvement of employment prospects was noted quite early on in the questionnaire analysis and gave momentum to the setting up of a Working Party (another idea to which members gave the thumbs-up sign) on careers in nutrition under the chairmanship of Dr Ann Walker. This Working Party is already quite well ahead with its investigations into the setting up of a professional organization for nutritionists and has been helped enormously in all its deliberations by the comments made in the questionnaire.

In conclusion then, we hope that the questionnaire has gone a fair way to answering the three questions posed by Professor Waterlow in 1984. Furthermore, we hope that members will already have noticed some changes occurring within the Society which will convince them that it was well worth filling in the questionnaire and that our time spent in its analysis has not been wasted.

\section{Acknowledgements}

We would like to thank Mrs S. M. V. Levitt, Mrs J. Bowles and Mr K. Symonds of the Dunn Nutrition Unit and Dr J. Kirtland for their help in questionnaire analysis. We are particularly grateful to Dr Ann Walker of the University of Reading, Dr Terry Kirk of Queen Margaret College, Edinburgh, and Dr Neville Belton of the Department of Child Life and Health, University of Edinburgh, for their invaluable assistance in the selection of questionnaire comments which accompany this paper. Finally, we thank all Nutrition Society Council members for their helpful comments on the compilation of the questionnaire and Professor J. C. Waterlow and Dr D. H. Buss, in particular, for their constructive criticisms of this manuscript. 